\title{
Thermodynamics and kinetics of the hydrolysis of atmospherically relevant organonitrates and organosulfates
}

\author{
K. S. Hu, A. I. Darer, and M. J. Elrod \\ Department of Chemistry and Biochemistry, Oberlin College, Oberlin, Ohio, USA \\ Received: 5 April 2011 - Published in Atmos. Chem. Phys. Discuss.: 10 May 2011 \\ Revised: 29 July 2011 - Accepted: 8 August 2011 - Published: 16 August 2011
}

\begin{abstract}
The presence of alcohol, organonitrate, and organosulfate species related to the gaseous precursor isoprene in ambient secondary organic aerosol (SOA) has stimulated investigations of the nature of SOA-phase chemical processing. Recent work has suggested that certain isoprene-derived organonitrates are able to efficiently convert to organosulfates and alcohols on ambient SOA. In order to better understand the structure activity relationships previously observed for the isoprene-derived organonitrates and organosulfates, the hydrolysis reactions of a number of monofunctional and difunctional organonitrates and organosulfates with varying carbon substitution properties were investigated. Nuclear magnetic resonance techniques were used to study the bulk phase aqueous reactions of these organonitrates and organosulfates in order to determine hydrolysis reaction rate and, in some cases, thermodynamics information. Electronic structure calculations were also carried out to determine the enthalpy of hydrolysis for these species, and for the previously studied isoprene-derived species. The results suggest that while organonitrates and organosulfates are thermodynamically unstable with respect to the corresponding alcohols at standard state, only the tertiary organonitrates (and perhaps some tertiary organosulfates) are able to efficiently hydrolyze on SOA timescales and acidities.
\end{abstract}

\section{Introduction}

Isoprene, the dominant biogenic volatile organic compound (Guenther et al., 2006), has been estimated to be the most important secondary organic aerosol (SOA) precursor (Carlton

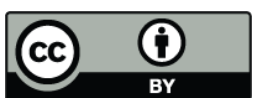

Correspondence to: M. J. Elrod (mjelrod@oberlin.edu) et al., 2009). SOA has been implicated in cardiovascular disease (Pope III and Dockery, 2006) and as an important driver of climate change (Hallquist et al., 2009). Seven different chemically distinct compounds based on the isoprene carbon backbone, containing epoxy, alcohol, nitrate, and/or sulfate functional groups, have now been identified in ambient SOA (Chan et al., 2010; Claeys et al., 2004; Wang et al., 2005; Surratt et al., 2007; Altieri et al., 2009; Gómez-González et al., 2008; Surratt et al., 2008; Froyd et al., 2010). Some of these compounds are undoubtedly formed from gas phase processing (Perring et al., 2009a, b; Lockwood et al., 2010; $\mathrm{Ng}$ et al., 2008), of isoprene, while other compounds (such as organosulfates) clearly indicate that additional chemical processing is occurring on ambient SOA particles themselves (Cole-Filipiak et al., 2010; Paulot et al., 2009; Surratt et al., 2010; Chan et al., 2010; Minerath et al., 2008, 2009; Eddingsaas et al., 2010; Szmigielski et al., 2010; Nozière et al., 2010; Rudzinski et al., 2009) We recently investigated some of the potential SOA-phase chemistry for isoprene-related compounds, and proposed an overall mechanism (shown in Fig. 1) that can rationalize the existence of five of the seven observed isoprene-derived SOA components (Darer et al., 2011). In particular, our study showed that tertiary organonitrates are unstable under typical SOA conditions (for typical acidities and atmospheric lifetimes), and can undergo nucleophilic substitution reactions with water and sulfate to form alcohols and organosulfates:

$$
\begin{aligned}
& \mathrm{RONO}_{2}+\mathrm{H}_{2} \mathrm{O} \rightarrow \mathrm{ROH}+\mathrm{HNO}_{3} \\
& \mathrm{RONO}_{2}+\mathrm{H}_{2} \mathrm{SO}_{4} \rightarrow \mathrm{ROSO}_{3} \mathrm{H}+\mathrm{HNO}_{3}
\end{aligned}
$$

On the other hand, the isoprene-derived tertiary organosulfates were found to undergo efficient hydrolysis only under conditions of strong acid catalysis $\left(\mathrm{H}^{+}\right.$as the specific catalytic species and $\mathrm{pH}<0$ ), 


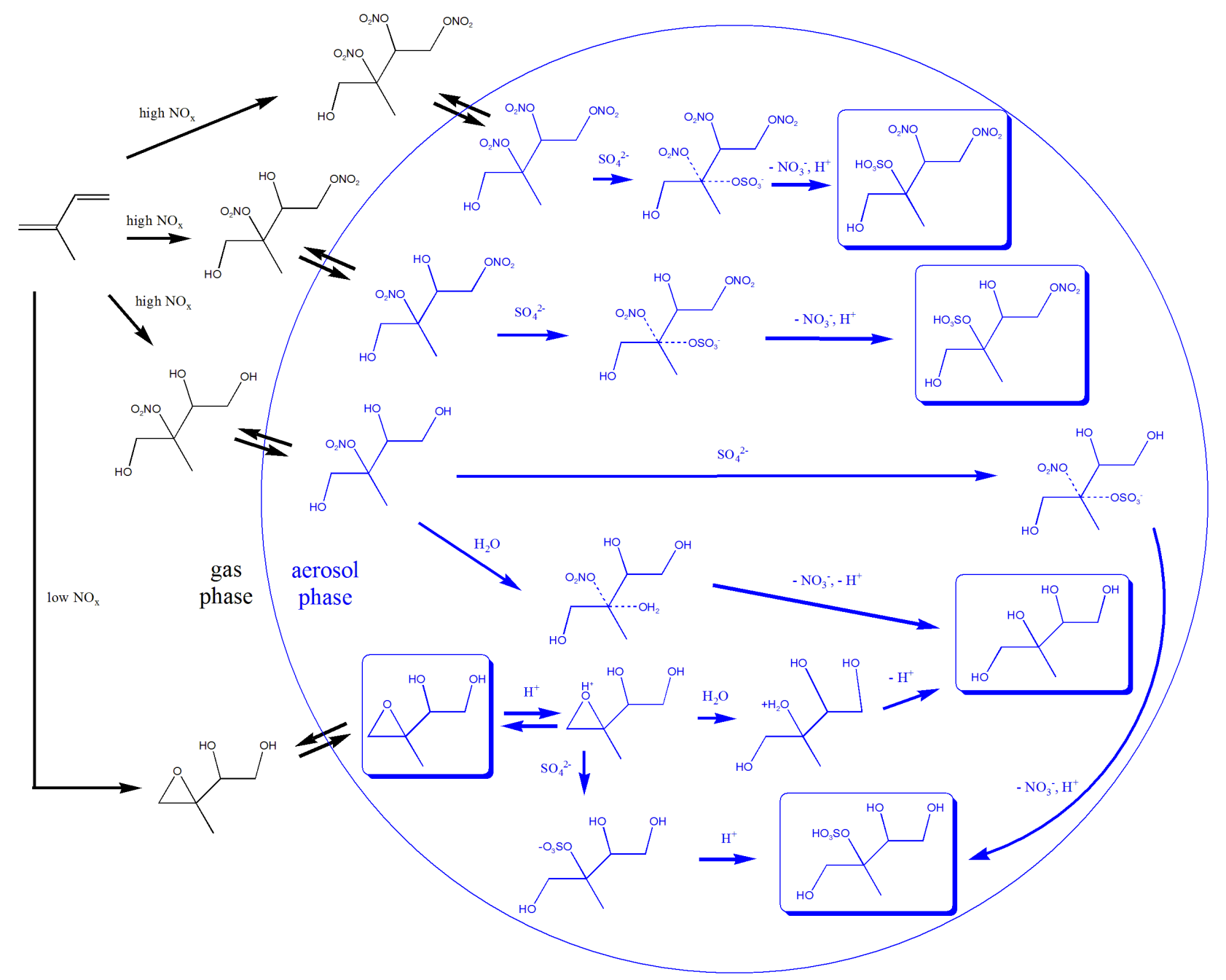

Fig. 1. Proposed mechanism for the formation of several isoprene-derived compounds observed in ambient SOA (enclosed by boxes).

$\mathrm{ROSO}_{3} \mathrm{H}+\mathrm{H}_{2} \mathrm{O} \rightarrow \mathrm{H}+\mathrm{ROH}+\mathrm{H}_{2} \mathrm{SO}_{4}$

and all primary organosulfates and organonitrates were found to be stable against hydrolysis for $\mathrm{pH}>0$. These findings are incorporated in Fig. 1, as tertiary sulfate functional groups and all primary and secondary nitrate and sulfate functional groups are assumed to be unreactive on SOA, while tertiary nitrate groups may be converted to alcohol or sulfate functionality. Recently, field (Day et al., 2010) and laboratory (Nguyen et al., 2011) studies have invoked efficient organonitrate hydrolysis as a process by which organonitrates are removed from aerosols, thus highlighting the potential significance of this chemistry in the atmosphere.

In the present study, we sought to explore whether these findings were specific to the isoprene-derived species, or were more generally applicable. Additionally, we were interested in determining whether the stability of primary and secondary organosulfates and organonitrates is dictated by the thermodynamics of the hydrolysis reactions, or by very slow hydrolysis rates. We were also motivated to investigate how the presence of adjacent functional groups affects the thermodynamics and kinetics of the hydrolysis reactions. Therefore, we chose to study a number of monofunctional and difunctional organonitrates and organosulfates with varying carbon substitution properties in order to supplement the structure-activity relationships that were revealed in our previous study of the isoprene-derived species (Darer et al., 2011). Nuclear magnetic resonance (NMR) techniques were used to study the bulk phase aqueous reactions of these organonitrates and organosulfates in order to determine hydrolysis reaction rate and, in some cases, thermodynamics information. Electronic structure calculations were also carried out to determine the enthalpy of hydrolysis for these species, and for the previously studied isoprenederived species. These results allow for a better understanding of the thermodynamics and kinetics of the chemical processing of organonitrates and organosulfates on SOA. 


\section{Methods}

\subsection{Syntheses of organonitrates and organosulfates}

Isopropyl nitrate was obtained commercially (SigmaAldrich). Ethyl nitrate was prepared according to the procedure developed earlier in our lab (Ranschaert et al., 2000). 1-nitrato-2-butanol, 2-nitrato-1-butanol, 3-nitrato-2-butanol, and 2-methyl-2-nitrato-1-butanol were prepared according to a previous procedure (Muthuramu et al., 1993). All other organonitrates were prepared in situ in the reaction solutions by nucleophilic attack of nitrate on epoxide precursors (Darer et al., 2011). For the thermodynamics experiments, the difunctional organosulfates were prepared in situ in the reaction solutions via alcohol esterification reactions with sulfuric acid (Minerath et al., 2008). For the kinetics experiments, the difunctional and the isoprene-derived organosulfates were prepared in situ in the reaction solutions by nucleophilic attack of sulfate on epoxide precursors. The monofunctional epoxide precursors were obtained commercially (Sigma-Aldrich).

\subsection{Preparation of reaction solutions}

All experiments were performed using deuterated acid/salt solutions for the purpose of NMR field locking. The acid/salt solutions were custom prepared using commercially available $96-98 \mathrm{wt} \% \quad \mathrm{D}_{2} \mathrm{SO}_{4}$ (Sigma-Aldrich), $70 \mathrm{wt} \%$ $\mathrm{DNO}_{3}$ (Sigma-Aldrich), $99.9 \% \mathrm{D}_{2} \mathrm{O}$ (Cambridge Isotope Lab, Inc.), $\mathrm{Na}_{2} \mathrm{SO}_{4}$ (Sigma-Aldrich), and $\mathrm{NaNO}_{3}$ (SigmaAldrich). To each solution, $0.1 \mathrm{wt} \%$ sodium 2,2-dimethyl-2silapentane-5-sulfonate (DSS, Cambridge Isotope Lab, Inc.) was added as an internal standard.

\subsection{Temperature dependence measurements of the hydrolysis equilibrium constant for difunctional butyl organosulfates}

These measurements were carried out in a similar fashion described earlier (Minerath et al., 2008). To $2.5 \mathrm{ml}$ of $65 \mathrm{wt} \% \mathrm{D}_{2} \mathrm{SO}_{4} / \mathrm{D}_{2} \mathrm{O}, 25 \mu \mathrm{l}$ of the precursor diol (either 1,2-butanediol or 2,3-butanediol; both obtained from SigmaAldrich) was added, and the solution was vigorously stirred for $3 \mathrm{~min}$. Some of this solution was transferred to a $5 \mathrm{~mm}$ NMR tube, and the tube was placed in a constant temperature bath for a period of $24 \mathrm{~h}$ (to insure the establishment of equilibrium). All ${ }^{1} \mathrm{H}$ NMR spectra were collected on a Varian $400 \mathrm{MHz}$ NMR Spectrometer. The variable temperature feature of the NMR spectrometer was used to maintain a fixed temperature during the collection of the spectrum. The relative amounts of diol and sulfate ol concentrations (needed to calculate the equilibrium constant) were calculated by peak integration of unique protons for each species, referenced to the 9 methyl protons at $0.00 \mathrm{ppm}$ from DSS.

\subsection{Hydrolysis kinetics measurements}

For the separately prepared organonitrates (ethyl nitrate, isopropyl nitrate, 1-nitrato-2-butanol, 2-nitrato-1-butanol, 3nitrato-2-butanol, and 2-methyl-2-nitrato-1-butanol), the reaction mixtures were prepared and subjected to NMR analysis at room temperature $(296 \pm 2 \mathrm{~K})$ as follows. A $5.0 \mathrm{ml}$ aliquot of the desired acid/salt solution was added to a $25 \mathrm{ml}$ Ehrlenmeyer flask and stirred. For the fast reacting tertiary organonitrates, the acid content was varied from $0-1 \mathrm{M}$ in the experiments, while the total sulfate or nitrate concentrations were usually held constant at $1 \mathrm{M}$. For the slow reacting primary and secondary organonitrates, highly concentrated sulfuric acid solutions were used (45-65 wt $\left.\% \mathrm{D}_{2} \mathrm{SO}_{4}\right)$. Next, $50 \mu \mathrm{l}(\sim 0.10 \mathrm{M})$ of the organonitrate reactant was added and a timer was started. After approximately $1 \mathrm{~min}$ of stirring to ensure solution homogeneity, an aliquot of the reaction mixture was loaded into an NMR tube and NMR spectral collection was started. The reaction time was recorded as the ending time of each $30 \mathrm{~s}$ NMR data collection period. Depending on the rate of reaction for the various species, the solutions were either monitored continuously for a total period of time of about one hour, or were monitored intermittently over a total period of time as long as two weeks. The relative amounts of the various species present were calculated by peak integration of unique protons for each species, referenced to the 9 methyl protons at $0.00 \mathrm{ppm}$ from DSS.

For the tertiary organonitrates and organosulfates prepared in situ from the nucleophilic attack of nitrate or sulfate on epoxides, the reaction mixtures were prepared and subjected to NMR analysis as follows. A $2.5 \mathrm{ml}$ aliquot of the acid/salt solution was added to a $10 \mathrm{ml}$ beaker and stirred. The $\mathrm{DNO}_{3}$ or $\mathrm{D}_{2} \mathrm{SO}_{4}$ content was varied from $0-4 \mathrm{M}$ in these experiments. For experiments with acidity concentrations of less than $1 \mathrm{M}$, the total nitrate or sulfate concentrations were held constant at $1 \mathrm{M}$. Next, $25 \mu \mathrm{l}(\sim 0.10 \mathrm{M})$ of the epoxide precursor was added and a timer was started. After approximately 1 min of stirring to ensure solution homogeneity, an aliquot of the reaction mixture was loaded into an NMR tube and NMR spectral collection was started. Typically, the epoxide precursors reacted away within minutes, and the resulting organonitrate or organosulfate products were subsequently monitored for periods as long as a few days. The relative amounts of the various species present were calculated by peak integration of unique protons for each species, referenced to the 9 methyl protons at $0.00 \mathrm{ppm}$ from DSS.

\subsection{FTIR analysis of gas evolution from the reaction of 3-nitrato-2-butanol in $55 \mathrm{wt} \% \mathrm{D}_{2} \mathrm{SO}_{4}$}

Because it was observed that many of the organonitrate reactions in concentrated sulfuric acid generated a gaseous product, a separate experiment was performed in which the gas product was quantitatively trapped and analyzed. $50 \mathrm{ml}$ of a $55 \mathrm{wt} \% \mathrm{D}_{2} \mathrm{SO}_{4} / \mathrm{D}_{2} \mathrm{O}$ solution was added to a $500 \mathrm{ml}$ round 
bottomed flask equipped with a stir bar. Next, $800 \mu$ of 3nitrato-2-butanol was added and the flask was quickly attached to a vacuum manifold ( $V \sim 100 \mathrm{ml}$ ) with an FTIR gas cell $(V \sim 200 \mathrm{ml})$ attached. The entire system was evacuated and then closed so that all of the evolved gas was collected in the $\sim 750 \mathrm{ml}$ available volume of the whole system. The gaseous product of the reaction was collected for two hours (a little more than one lifetime for the hydrolysis of 3-nitrato2-butanol at this acid concentration). The FTIR gas cell was then detached from the system, and the FTIR spectrum was collected.

\subsection{Modified computational G2MS method for the calculation of $\Delta H_{\text {hyd }}$}

Geometries and energies of the relevant reactants and products for each hydrolysis reaction system (which are simply species-specific versions of Reactions R1 and R3) were calculated using a modified version of the G2MS compound method (MG2MS) (Froese et al., 1997) a variation on G2 theory (Curtiss et al., 1997). The Polarizable Continuum Model (PCM) method (Tomasi et al., 2005) was used to account for the effects of aqueous solvation on the reactant and product properties. All calculations were carried out with the Gaussian 03 computational suite (Frisch et al., 2003). Each stationary point was confirmed as a potential energy minimum by inspection of the calculated frequencies. The overall energy expression for the MG2MS scheme is defined in Eq. (1):

$$
\begin{gathered}
E_{\mathrm{G} 2 \mathrm{MS}}=E_{\mathrm{CCSD}(T) / 6-31 \mathrm{G}(d)}+E_{\mathrm{MP} 2 / 6-311+\mathrm{G}(2 d f, 2 p)} \\
-E_{\mathrm{MP} 2 / 6-31 \mathrm{G}(d)}+\mathrm{HLC}
\end{gathered}
$$

where HLC is an empirically-defined correction term with HLC $=A n_{\alpha}+B n_{\beta}$ where $n_{\alpha}$ and $n_{\beta}$ are the number of $\alpha$ and $\beta$-electrons, respectively, and the constants $A$ and $B$ are 6.06 and $0.19 \mathrm{mH}$, respectively. Our previous MG2MS results for atmospherically relevant systems (including radicals and ions) indicate that the MG2MS calculated thermodynamic properties (enthalpies of reaction) are typically accurate to within $2.5 \mathrm{kcal} \mathrm{mol}^{-1}$ for systems similar to those under study here (Cappa and Elrod, 2001).

\section{Results}

\subsection{Experimental determination of thermodynamics parameters for the hydrolysis of organosulfates}

The temperature dependent equilibrium constants for the hydrolysis of sulfates (Reaction R3) were calculated from the following expression:

$$
K=\frac{a_{\mathrm{ROH}} a_{\mathrm{H}_{2} \mathrm{SO}_{4}}}{a_{\mathrm{ROSO}_{3} \mathrm{H} a_{\mathrm{H}_{2} \mathrm{O}}}}
$$

As discussed in the experimental section, the relative concentrations (activities) for the organosulfate and alcohol species were obtained directly from the NMR spectra. The activities for $\mathrm{H}_{2} \mathrm{SO}_{4}\left(a_{\mathrm{H}_{2} \mathrm{SO}_{4}}=a_{\mathrm{HSO}_{4}^{-}}+a_{\mathrm{SO}_{4}^{2-}}\right)$ and $\mathrm{H}_{2} \mathrm{O}$ were calculated from the Aerosol Inorganics Model (AIM) (Wexler and Clegg, 2002) for each of the solutions. For the $65 \mathrm{wt} \%$ $\mathrm{D}_{2} \mathrm{SO}_{4}$ solutions used in the present experiments, $a_{\mathrm{H}_{2} \mathrm{SO}_{4}}=$ 67.7 and $a_{\mathrm{H}_{2} \mathrm{O}}=0.591$. The temperature dependent equilibrium constants were then analyzed according to the van't Hoff equation,

$$
-R T \ln K=\Delta G_{\text {hyd }}=\Delta H_{\text {hyd }}-T \Delta S_{\text {hyd }}
$$

in order to determine the $\Delta H_{\text {hyd }}$ and $-T \Delta S_{\text {hyd }}$ contributions to the free energy of hydrolysis, $\Delta G_{\text {hyd }}$, for standard state conditions (i.e. unity activities). As the equilibrium constant $\mathrm{K}$ is the actual experimental property measured, a linear regression analysis of $\ln K$ vs. $1 / T$ was performed to yield the thermodynamic parameters $\Delta H_{\text {hyd }}$ and $-T \Delta S_{\text {hyd }}$. The monofunctional primary organosulfate hydrolysis thermodynamics parameters were previously reported for the methyl (Wolfenden and Yuan, 2007), the ethyl (Clark and Williams, 1957) and the 1-butyl (Minerath et al., 2008) systems (which were measured at varying sulfuric acid and water activities) were reanalyzed in terms of this standard definition of the equilibrium constant, and the thermodynamic parameters for these systems are reported in Table 1. The thermodynamic parameters obtained for the difunctional primary or secondary butyl organosulfate systems in the present work are reported in Table 2. Since $\Delta G_{\text {hyd }}$ is negative for all systems at standard state, it is clear that the alcohol species are thermodynamically favored over the organosulfate species for these systems. Furthermore, since no tertiary organosulfate species could be detected (NMR sensitivity considerations indicate that these species were present at $<1 \%$ of the corresponding alcohol concentration) at equilibrium for similarly concentrated sulfuric acid solutions in the present work, $\Delta G_{\text {hyd }}$ must be even more negative $\left(\Delta G_{\mathrm{hyd}}<-2 \mathrm{kcal} \mathrm{mol}^{-1}\right.$ ) for these systems than it is for the primary and secondary organosulfate systems. No organonitrate species could be detected at equilibrium in any of the experiments. Because much lower $\mathrm{DNO}_{3}$ concentrations $(<1 \mathrm{M})$ had to be used in the corresponding organonitrate hydrolysis experiments (due to the presence of the strongly oxidizing nitronium ion at high $\mathrm{DNO}_{3}$ concentrations), a similar analysis yields a more positive upper limit for the free energy of hydrolysis for organonitrates at standard state: $\Delta G_{\text {hyd }}<-0.2 \mathrm{kcal} \mathrm{mol}^{-1}$. However, it is clear that alcohol species are thermodynamically favored at standard state over all of the organosulfate and organonitrates considered in this study. Of course, the actual alcohol to organosulfate ratio under atmospheric conditions must be calculated from Eq. (2) for a specific set of water and sulfuric acid activities. For example, an aerosol with an effective sulfuric acid concentration of $65 \mathrm{wt} \%$ (the concentration used in many of the equlibrium constant experiments) would be expected to have an alcohol to organosulfate ratio that is much 
Table 1. Thermodynamic and kinetic parameters for the hydrolysis of monofunctional organonitrates and organosulfates.

\begin{tabular}{|c|c|c|c|c|c|c|}
\hline & \multicolumn{4}{|c|}{$\mathrm{X}=\mathrm{OSO}_{3} \mathrm{H}$} & \multicolumn{2}{|c|}{$\mathrm{X}=\mathrm{ONO}_{2}$} \\
\hline & $\begin{array}{r}\Delta H_{\mathrm{hyd}}^{\exp } \\
\left(\mathrm{kcal} \mathrm{mol}^{-1}\right)\end{array}$ & $\begin{array}{c}\Delta H_{\mathrm{hyd}}^{\mathrm{comp}} \\
\left(\mathrm{kcal} \mathrm{mol}^{-1}\right)\end{array}$ & $\begin{array}{r}-T \Delta S_{\mathrm{hyd}}^{\exp } \\
\left(\mathrm{kcal} \mathrm{mol}^{-1}\right)\end{array}$ & $\begin{array}{r}\tau_{\text {hyd }}^{\mathrm{a}} \\
(\mathrm{h})\end{array}$ & $\begin{array}{c}\Delta H_{\mathrm{hyd}}^{\mathrm{comp}} \\
\left(\mathrm{kcal} \mathrm{mol}^{-1}\right)\end{array}$ & $\begin{array}{r}\tau_{\text {hyd }}^{\mathrm{a}} \\
\text { (h) }\end{array}$ \\
\hline $\mathrm{CH}_{3} \mathrm{X}$ & $0.0^{\mathrm{b}}$ & 0.1 & $-2.1^{b}$ & $120^{\mathrm{c}}$ & 2.5 & \\
\hline $\mathrm{CH}_{3} \mathrm{CH}_{2} \mathrm{X}$ & $0.4^{\mathrm{d}}$ & -0.1 & $-3.4^{\mathrm{d}}$ & $100^{\mathrm{c}}$ & 2.9 & 2.5 \\
\hline $\mathrm{CH}_{3} \mathrm{CH}(\mathrm{X}) \mathrm{CH}_{3}$ & & 0.4 & & & 2.5 & 2.2 \\
\hline $\mathrm{CH}_{3} \mathrm{CH}_{2} \mathrm{CH}_{2} \mathrm{CH}_{2} \mathrm{X}$ & $1.6^{\mathrm{c}}$ & 1.2 & $-4.3^{\mathrm{c}}$ & $260^{\mathrm{c}}$ & 2.4 & \\
\hline $\mathrm{CH}_{3} \mathrm{CH}_{2} \mathrm{CH}(\mathrm{X}) \mathrm{CH}_{3}$ & & 1.1 & & & 2.4 & \\
\hline$\left(\mathrm{CH}_{3}\right)_{3} \mathrm{CX}$ & & -0.7 & & & 0.0 & \\
\hline
\end{tabular}

${ }^{a}$ The acid-catalyzed mechanism hydrolysis lifetime (for $55 \mathrm{wt} \% \mathrm{D}_{2} \mathrm{SO}_{4}$ solution) is given.

b Wolfenden and Yuan (2007)

${ }^{c}$ Consult reference (Minerath et al., 2008) for full discussion of acid dependence of kinetics of hydrolysis.

${ }^{\mathrm{d}}$ Clark and Williams (1957)

Table 2. Thermodynamic and kinetic parameters for the hydrolysis of difunctional organonitrates and organosulfates.

\begin{tabular}{|c|c|c|c|c|c|c|}
\hline & \multicolumn{4}{|c|}{$\mathrm{X}=\mathrm{OSO}_{3} \mathrm{H}$} & \multicolumn{2}{|c|}{$\mathrm{X}=\mathrm{ONO}_{2}$} \\
\hline & $\begin{array}{r}\Delta H_{\text {hyd }}^{\text {exp }} \\
\left(\mathrm{kcal} \mathrm{mol}^{-1}\right)\end{array}$ & $\begin{array}{r}\Delta H_{\mathrm{hyd}}^{\mathrm{comp}} \\
\left(\mathrm{kcal} \mathrm{mol}^{-1}\right)\end{array}$ & $\begin{array}{r}-T \Delta S_{\text {hyd }}^{\text {exp }} \\
\left(\mathrm{kcal} \mathrm{mol}{ }^{-1}\right)\end{array}$ & $\begin{array}{r}\tau_{\text {hyd }}^{\mathrm{a}} \\
\text { (h) }\end{array}$ & $\begin{array}{r}\Delta H_{\text {hyd }}^{\text {comp }} \\
\left(\mathrm{kcal} \mathrm{mol}^{-1}\right)\end{array}$ & $\begin{array}{r}\tau_{\text {hyd }}^{\mathrm{a}} \\
\text { (h) }\end{array}$ \\
\hline $\mathrm{HOCH}_{2} \mathrm{CH}_{2} \mathrm{X}$ & & -1.6 & & $71^{b}$ & 0.0 & \\
\hline $\mathrm{CH}_{3} \mathrm{CH}(\mathrm{OH}) \mathrm{CH}_{2} \mathrm{X}$ & & 0.0 & & & 0.1 & \\
\hline $\mathrm{CH}_{3} \mathrm{CH}(\mathrm{X}) \mathrm{CH}_{2} \mathrm{OH}$ & & -2.3 & & & -0.2 & \\
\hline $\mathrm{CH}_{3} \mathrm{CH}_{2} \mathrm{CH}(\mathrm{OH}) \mathrm{CH}_{2} \mathrm{X}$ & 0.0 & 0.1 & -4.3 & & 0.5 & 1.7 \\
\hline $\mathrm{CH}_{3} \mathrm{CH}_{2} \mathrm{CH}(\mathrm{X}) \mathrm{CH}_{2} \mathrm{OH}$ & 0.0 & -0.2 & -3.9 & & 2.0 & 1.9 \\
\hline $\mathrm{CH}_{3} \mathrm{CH}(\mathrm{OH}) \mathrm{CH}(\mathrm{X}) \mathrm{CH}_{3}$ & -0.6 & 1.3 & -2.8 & & 2.1 & 1.5 \\
\hline$\left(\mathrm{CH}_{3}\right)_{2}\left(\mathrm{CH}_{2} \mathrm{OH}\right) \mathrm{CX}$ & & -2.4 & & 2.5 & -2.2 & 0.030 \\
\hline$\left(\mathrm{CH}_{3}\right)_{2}\left(\mathrm{CH}_{2} \mathrm{X}\right) \mathrm{COH}$ & & 0.2 & & & 0.5 & \\
\hline$\left(\mathrm{CH}_{3}\right)_{2} \mathrm{C}(\mathrm{X}) \mathrm{CH}(\mathrm{OH}) \mathrm{CH}_{3}$ & & -3.1 & & 31 & -1.7 & 0.028 \\
\hline$\left(\mathrm{CH}_{3}\right)_{2} \mathrm{C}(\mathrm{OH}) \mathrm{CH}(\mathrm{X}) \mathrm{CH}_{3}$ & & 0.4 & & & 0.8 & \\
\hline$\left(\mathrm{CH}_{3}\right)_{2} \mathrm{CH}(\mathrm{OH}) \mathrm{CH}(\mathrm{X})\left(\mathrm{CH}_{3}\right)_{2}$ & & -3.1 & & 22 & -2.5 & 0.019 \\
\hline
\end{tabular}

${ }^{a}$ For tertiary systems, the neutral mechanism hydrolysis lifetime is given. For primary and secondary systems, the acid-catalyzed mechanism hydrolysis lifetime (for 55 wt $\%$ $\mathrm{D}_{2} \mathrm{SO}_{4}$ solution) is given.

b Minerath et al. (2008)

lower than that predicted at standard state (lower by the ratio $\left.a_{\mathrm{H}_{2} \mathrm{SO}_{4}} / a_{\mathrm{H}_{2} \mathrm{O}}=0.591 / 67.7=0.00873\right)$.

\subsection{Computational determination of $\Delta H_{\text {hyd }}$ for the hydrolysis of organonitrates and organosulfates}

While it would be preferable to obtain computational estimates for $\Delta G_{\mathrm{hyd}}$, the ab initio calculation of the $-T \Delta S_{\mathrm{hyd}}$ contribution to the free energy change for reactions in aqueous solutions is not straightforward (Kua et al., 2008). Therefore, we report only computational $\Delta H_{\text {hyd }}$ values in Tables $1-3$ for the various species under study in the present work. However, since the experimental results for the hydrolysis of organosulfates suggest that $-T \Delta S_{\text {hyd }}$ for the hydrolysis of the primary organosulfates is confined to a rel- atively narrow range, -2.8 to $-4.3 \mathrm{kcal} \mathrm{mol}^{-1}$, a hybrid computational/experimental $\Delta G_{\text {hyd }}$ value can be estimated from the computational $\Delta H_{\text {hyd }}$ values. For the systems for which experimental $\Delta H_{\text {hyd }}$ values are available, it is clear that the accuracy of the computational $\Delta H_{\text {hyd }}$ method $\left(\leq 2 \mathrm{kcal} \mathrm{mol}^{-1}\right)$ is within the expected overall energy accuracy of the MG2MS method.

There are several trends apparent in the calculated $\Delta H_{\text {hyd }}$ values. In almost every case, $\Delta H_{\text {hyd }}$ is calculated to be more positive for the hydrolysis of the organonitrate (ranging from 0.3 to $3.0 \mathrm{kcal} \mathrm{mol}^{-1}$ more positive than the corresponding organosulfate) to the corresponding alcohol. Therefore, the computational results suggest that the organonitrates are somewhat enthalpically more stable than are the organosulfates with respect to the corresponding alcohols, 


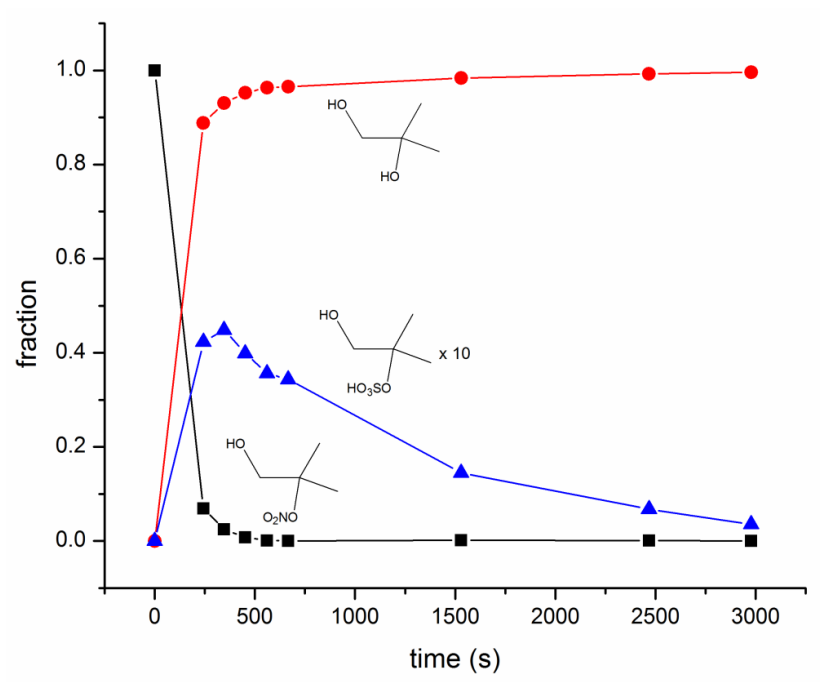

Fig. 2. Raw kinetics data for the reaction of 2-methyl-2-nitrato-1propanol in $2 \mathrm{M} \mathrm{D}_{2} \mathrm{SO}_{4}$.

although the differences are often less than the accuracy of the MG2MS approach. Since there is no experimental estimate for the $-T \Delta S_{\text {hyd }}$ contribution to $\Delta G_{\text {hyd }}$ for the hydrolysis of organonitrates (because $K$ is immeasurably large), a direct isoergic (free energy) comparison between organonitrates and organosulfates cannot be made. Nonetheless, since $\Delta G_{\text {hyd }}<-0.2 \mathrm{kcal} \mathrm{mol}^{-1}$ was experimentally determined to be the most positive upper limit for the hydrolysis of organonitrates and the computed $\Delta H_{\text {hyd }}$ values are as large as $+2.9 \mathrm{kcal} \mathrm{mol}^{-1}$ for the systems for which the $\Delta G_{\text {hyd }}$ upper limit was measured, it does appear that the $-T \Delta S_{\text {hyd }}$ contribution for the hydrolysis of organonitrates is on the same order $\left(\sim-3 \mathrm{kcal} \mathrm{mol}^{-1}\right)$ or more negative than the corresponding $-T \Delta S_{\text {hyd }}$ contribution for the hydrolysis of organosulfates. In any case, the existing computational and experimental data suggest that the free energies of hydrolysis for organonitrates and organosulfates are probably quite similar. The results also suggest that tertiary organonitrates and organosulfates are enthalpically less stable with respect to the corresponding alcohols than are the primary and secondary species. Finally, the presence of adjacent $\mathrm{OH}$ groups also seems to decrease the enthalpic stability of organonitrates and organosulfates with respect to the alcohols. All three of these trends are illustrated by comparing particular $\Delta H_{\text {hyd }}$ values (from Tables $1-$ 3): $\mathrm{CH}_{3} \mathrm{CH}_{2} \mathrm{CH}_{2} \mathrm{CH}_{2} \mathrm{ONO}_{2}$ (primary nitrate, $\Delta H_{\text {hyd }}=+2.4$ kcal $\mathrm{mol}^{-1}$ ), $\mathrm{CH}_{3} \mathrm{CH}_{2} \mathrm{CH}_{2} \mathrm{CH}_{2} \mathrm{OSO}_{3} \mathrm{H}$ (primary sulfate, $\left.\Delta H_{\text {hyd }}=+1.2 \mathrm{kcal} \mathrm{mol}^{-1}\right),\left(\mathrm{CH}_{3}\right)_{3} \mathrm{COSO}_{3} \mathrm{H}$ (tertiary sulfate, $\left.\Delta H_{\text {hyd }}=-0.7 \mathrm{kcal} \mathrm{mol}^{-1}\right),\left(\mathrm{CH}_{3}\right)_{2}\left(\mathrm{CH}_{2} \mathrm{OH}\right) \mathrm{COSO}_{3} \mathrm{H}$ (tertiary sulfate, 1 adjacent $\mathrm{OH}$ group, $\Delta H_{\mathrm{hyd}}=-2.4 \mathrm{kcal}$ $\mathrm{mol}^{-1}$ ), and 2-methyl-2-sulfato-1,3,4-butanetriol (tertiary sulfate, 2 adjacent $\mathrm{OH}$ groups, $\Delta H_{\mathrm{hyd}}=-5.6 \mathrm{kcal} \mathrm{mol}^{-1}$ ).

\subsection{Kinetics of hydrolysis of tertiary organonitrates and organosulfates}

In our previous study of isoprene-derived tertiary organonitrates, we found that the kinetics of hydrolysis was not aciddependent for solutions ranging from $0-1 \mathrm{M} \mathrm{DNO}_{3}$. Therefore a simple first order rate law was used to analyze the hydrolysis kinetics,

$$
-\frac{d\left[\mathrm{RONO}_{2}\right]}{d t}=k_{\mathrm{n}}^{\mathrm{N}}\left[\mathrm{RONO}_{2}\right]
$$

where $k_{\mathrm{n}}^{\mathrm{N}}$ is the first order neutral mechanism organo nitrate hydrolysis rate constant. Similarly, the kinetics of hydrolysis of the tertiary organonitrates investigated in the present work were also found to obey this simple rate law for acid concentrations up to $1 \mathrm{M} \mathrm{DNO}_{3}$ and $2 \mathrm{M} \mathrm{D}_{2} \mathrm{SO}_{4}$. Figure 2 shows the raw kinetics data for the hydrolysis of 2-methyl-2-nitrato-1propanol (the concentration is expressed as the fraction of the total concentration of all species quantified) carried out in $2 \mathrm{M} \mathrm{D}_{2} \mathrm{SO}_{4}$ (in which 2-methyl-2-sulfato-1-propanol is observed as an intermediate in the hydrolysis process - an aspect that will be discussed in a later section). Figure 3 shows the first order kinetics analysis of the organonitrate data from Fig. 2 that is used to determine $k_{\mathrm{n}}^{\mathrm{N}}$. Table 2 contains the lifetimes $\left(\tau_{\text {hyd }}=\frac{1}{k_{\mathrm{n}}^{\mathrm{N}}}\right)$ for hydrolysis of the tertiary organonitrates studied in the present work, and Table 3 includes the hydrolysis lifetime for the isoprene-derived tertiary organonitrate studied in our previous work (Darer et al., 2011).

Again paralleling our findings for the isoprene-derived tertiary organosulfates, it was found that a neutral hydrolysis mechanism was operative for acid concentrations less than about $0.1 \mathrm{M}$, while an acid-dependent mechanism was dominant at higher acid concentrations for the tertiary organosulfates investigated in the present study. In order to explore the acid catalysis in more detail, $\mathrm{D}_{2} \mathrm{SO}_{4}$ concentrations as high as $4 \mathrm{M}$ were used. Due to the use of these highly concentrated solutions, AIM (Wexler and Clegg, 2002) was used to calculate proton activities ( $a_{\mathrm{H}+}$ in molal units) for use in the kinetics analysis. Therefore, the tertiary organosulfate hydrolysis kinetics data was analyzed according to a two term rate law

$$
-\frac{d\left[\mathrm{ROSO}_{3} \mathrm{H}\right]}{d t}=k_{\mathrm{n}}^{\mathrm{S}}\left[\mathrm{ROSO}_{3} \mathrm{H}\right]+k_{\mathrm{H}+}^{\mathrm{S}} a_{\mathrm{H}+}\left[\mathrm{ROSO}_{3} \mathrm{H}\right]
$$

where $k_{\mathrm{n}}^{\mathrm{S}}$ is the first order neutral mechanism organosulfate hydrolysis rate constant and $k_{\mathrm{H}+}^{\mathrm{S}}$ is the second order aciddependent mechanism organosulfate hydrolysis rate constant.

The integrated raw law for Eq. (5) is

$-\ln \frac{\left[\mathrm{ROSO}_{3} \mathrm{H}\right]}{\left[\mathrm{ROSO}_{3} \mathrm{H}\right]_{\mathrm{o}}}=k_{\mathrm{n}}^{\mathrm{S}} t+k_{\mathrm{H}+}^{\mathrm{S}} a_{\mathrm{H}+} t$

When the acid-dependent term is dominant, the integrated rate law can be written as 
Table 3. Thermodynamic and kinetic parameters for the hydrolysis of isoprene-derived organonitrates and organosulfates.

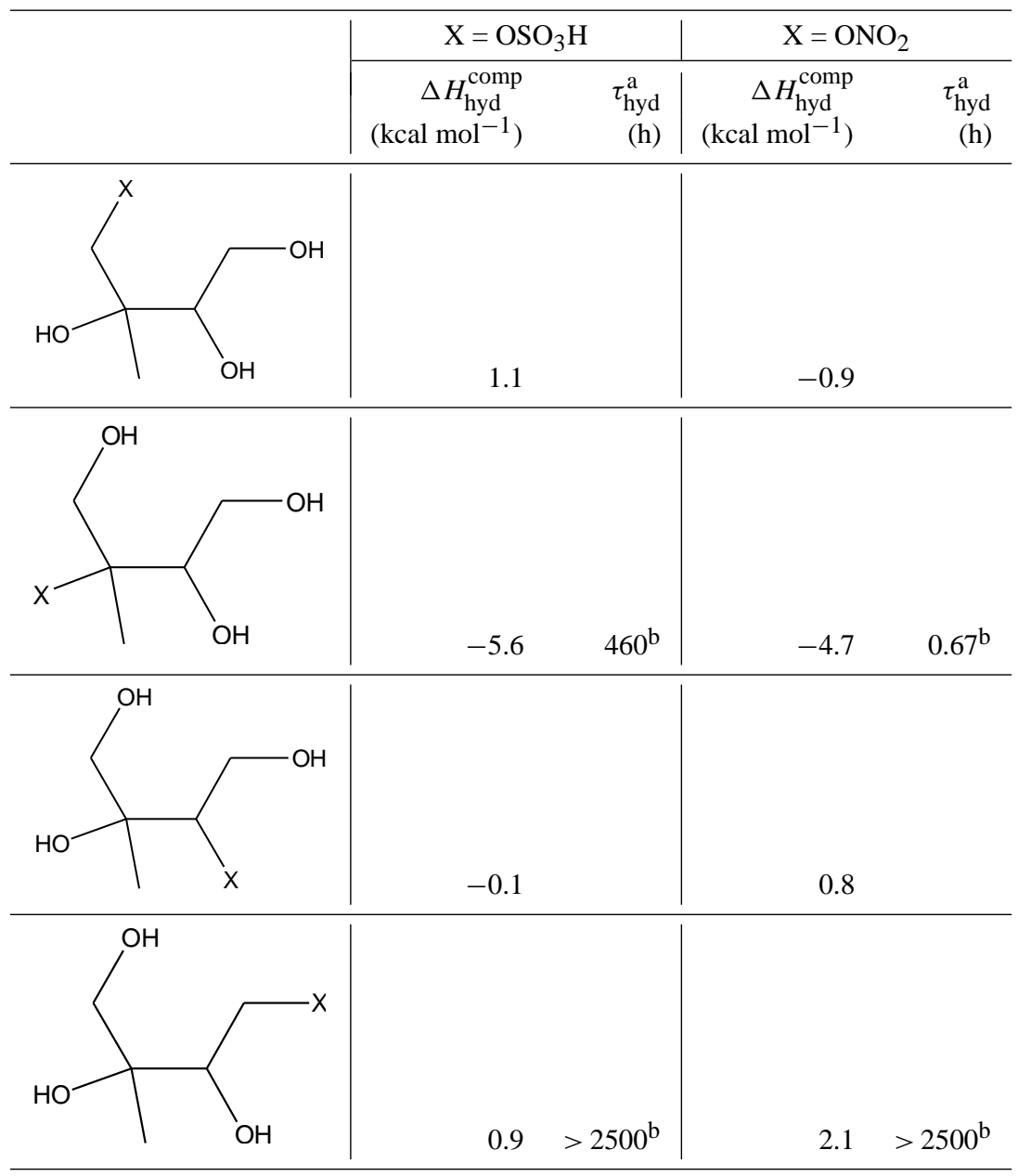

a The neutral mechanism hydrolysis lifetime is given.

${ }^{\mathrm{b}}$ Darer et al. (2011)

$-\ln \frac{\left[\mathrm{ROSO}_{3} \mathrm{H}\right]}{\left[\mathrm{ROSO}_{3} \mathrm{H}\right]_{\mathrm{o}}}=k_{\mathrm{H}+}^{\mathrm{S}} a_{\mathrm{H}+} t=k_{\mathrm{eff}}^{\mathrm{S}} t$

where $k_{\mathrm{eff}}^{\mathrm{S}}=k_{\mathrm{H}+}^{\mathrm{S}} a_{\mathrm{H}+}$.

Therefore, a plot of $k_{\text {eff }}^{\mathrm{S}}$ vs. $a_{\mathrm{H}+}$ yields the value of $k_{\mathrm{H}+}^{\mathrm{S}}$. Figure 3 shows one of the pseudo first order kinetics plots for the hydrolysis of 2-methyl-2-sulfato-1-propanol (using the raw data from Fig. 2) that was used to determine one of the $k_{\mathrm{eff}}^{\mathrm{S}}$ values needed to derive $k_{\mathrm{H}+}^{\mathrm{S}}$. Formal acid dependent measurements were carried out for 2-methyl-2-sulfato-1propanol, and $k_{\mathrm{H}+}^{\mathrm{S}}$ was determined to be $2.8 \times 10^{-4} \mathrm{~m}^{-1} \mathrm{~s}^{-1}$ (the statistical uncertainty in this value is on the order of $20 \%$ ). The presence of an acid-dependent mechanism for tertiary organosulfate hydrolysis was previously attributed to the fact that a sulfate group will be a more efficient leaving group for hydrolysis if the organosulfate species has an overall neutral charge (singly protonated sulfate group) (Darer et al., 2011). Table 2 contains the neutral mechanism lifetimes $\left(\tau_{\text {hyd }}=\frac{1}{k_{\mathrm{n}}^{\mathrm{S}}}\right)$ for the tertiary organosulfates under study in the present work, and Table 3 includes the hydrolysis lifetime for the isoprene-derived tertiary organosulfate studied in our previous work (Darer et al., 2011).

The neutral hydrolysis mechanism lifetimes for the tertiary organonitrates under study here (all with one adjacent $\mathrm{OH}$ group) were found to be very short, between 0.019 and $0.030 \mathrm{~h}$, which are slightly shorter than the hydrolysis lifetimes previously determined for isoprene-derived organonitrates with one adjacent $\mathrm{OH}$ group $\left(\tau_{\mathrm{hyd}}=0.061-0.12 \mathrm{~h}\right.$ ) (Darer et al., 2011). However, the particular isoprene-derived organonitrate believed to be relevant in atmospheric chemistry (2-methyl-2-nitrato-1,3,4-butanetriol) has two adjacent $\mathrm{OH}$ groups and was previously found to have a significantly longer hydrolysis lifetime $\left(\tau_{\text {hyd }}=0.67 \mathrm{~h}\right)$. 


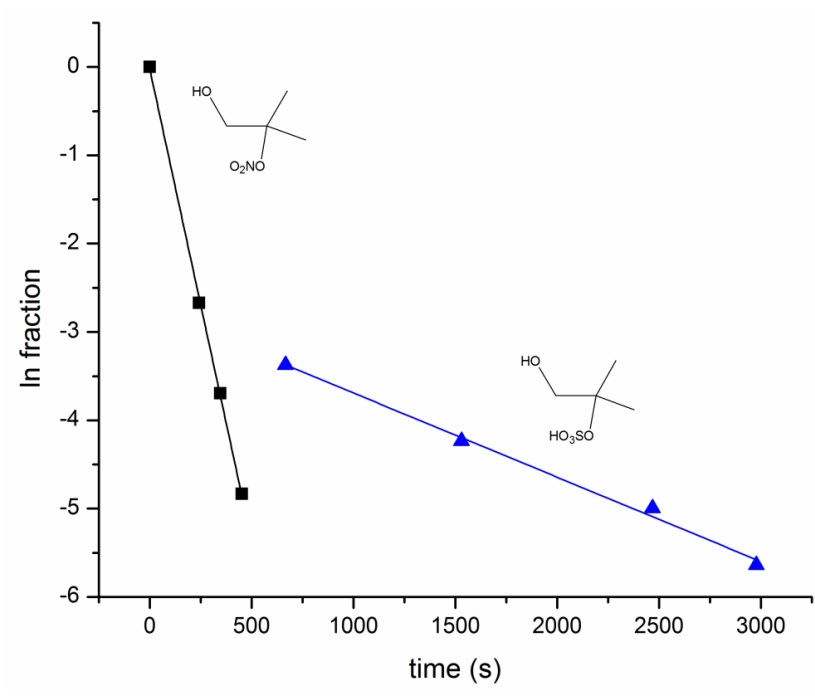

Fig. 3. Pseudo first order kinetics analysis for the hydrolysis of 2-methyl-2-nitrato-1-propanol and 2-methyl-2-sulfato-1-propanol from the data in Fig. 2.

The neutral hydrolysis mechanism lifetimes for the tertiary organosulfates under study here (all with one adjacent $\mathrm{OH}$ group) were found to be significantly longer than was found for the corresponding organonitrates: between 2.5 and $31 \mathrm{~h}$. These lifetimes were more or less similar to the hydrolysis lifetimes previously determined for isoprene-derived organosulfates with one adjacent $\mathrm{OH}$ group ( $\tau_{\text {hyd }}=20-62 \mathrm{~h}$ ) (Darer et al., 2011). The particular isoprene-derived organosulfate believed to be relevant in atmospheric chemistry (2-methyl-2-sulfato-1,3,4-butanetriol) has two adjacent $\mathrm{OH}$ groups and was found to have a significantly longer hydrolysis lifetime $\left(\tau_{\mathrm{hyd}}=460 \mathrm{~h}\right)$. However, the acid-dependent rate constants, $k_{\mathrm{H}+}^{\mathrm{S}}$, for 2-methyl-2sulfato-1-propanol and 2-methyl-2-sulfato-1,3,4-butanetriol were found to be similar, 2.8 and $2.3 \times 10^{-4} \mathrm{~m}^{-1} \mathrm{~s}^{-1}$, respectively (note that we are taking the opportunity here to correct a typo for the 2-methyl-2-sulfato-1,3,4-butanetriol rate constant previously reported, Darer et al., 2011).

Previously, we reported that the hydrolysis of 1,2-epoxy isoprene (methyl vinyl oxirane) was rapid at neutral $\mathrm{pH}$ (whereas all other epoxides studied to date require acid catalysis in order to achieve measureable hydrolysis rates), and that no sulfate products were detected even when the hydrolysis was performed at high sulfate concentrations (Minerath et al., 2009). The facile hydrolysis of 1,2-epoxy isoprene is likely related to the unusual stability of the allylically stabilized tertiary carbocation intermediate. As we pointed out in our previous work on the hydrolysis of isoprene-derived organosulfates (Darer et al., 2011), there appears to be a strong correlation between the values of epoxide hydrolysis rate constants (Cole-Filipiak et al., 2010; Minerath and Elrod, 2009; Minerath et al., 2009) and the values of organosul- fate and organonitrate hydrolysis rate constants for species with identical carbon backbones. The present work provides further support for the existence of this correlation. Since 1,2-epoxy isoprene has an unusually large hydrolysis rate constant, we now attribute the lack of an observed organosulfate product from the reaction of 1,2-epoxy isoprene to the (fleeting) existence of a very short-lived $\left(\tau_{\text {hyd }}<0.05 \mathrm{~h}\right)$ tertiary organosulfate product. Therefore, for the special case where hydrolysis leads to allylically stabilized tertiary carbocation intermediates, the kinetics of organosulfate hydrolysis can be very efficient indeed.

Supporting our previous supposition based on the kinetics of hydrolysis of isoprene-derived species, the new results suggest that a more general hypothesis concerning the greater kinetic efficiency of hydrolysis of tertiary organonitrates as compared to tertiary organosulfates is warranted. It also appears to generally be the case that the number of adjacent $\mathrm{OH}$ groups is inversely proportional to the hydrolysis rates for both tertiary organonitrates and organosulfates.

In our previous work concerning the hydrolysis of isoprene-derived organonitrates, we reported that that these species could be (temporarily) transformed to organosulfates if the organonitrate hydrolysis was carried out in the presence of sulfate (Darer et al., 2011). Therefore, in order to explore the generality of this finding, we performed experiments in which 2-methyl-2-nitrato-1-propanol was added to $\mathrm{D}_{2} \mathrm{SO}_{4}$ solutions. The NMR spectra from these experiments (the kinetics results for a $2 \mathrm{M} \mathrm{D}_{2} \mathrm{SO}_{4}$ experiment are shown in Fig. 2) clearly showed the presence of 2methyl-2-sulfato-1-propanol as an intermediate in this reaction system. In order to test whether organosulfate intermediates would also form in the presence of significant nitrate levels, we performed an additional experiment in which 2-methyl-2-nitrato-1-propanol was added to a $0.01 \mathrm{M}$ $\mathrm{D}_{2} \mathrm{SO}_{4} / 1 \mathrm{M} \mathrm{Na}_{2} \mathrm{SO}_{4} / 1 \mathrm{M} \mathrm{NaNO}{ }_{3}$ solution. Once again, 2methyl-2-sulfato-1-propanol was observed as an intermediate, indicating that organonitrate to organosulfate conversion can occur even when inorganic nitrate and sulfate concentrations are similar.

\subsection{Kinetics of hydrolysis of primary and secondary organonitrates}

As we found in our previous study of the hydrolysis of primary organosulfates (Minerath et al., 2008), extremely high sulfuric acid concentrations were required to catalyze the hydrolysis of the primary and secondary organonitrates under study in the present work. Tables 1 and 2 report the hydrolysis lifetimes $\left(\tau_{\text {hyd }}=\frac{1}{k_{\mathrm{n}}^{\mathrm{S}}}\right)$ previously determined for primary organosulfates as well as the new hydrolysis lifetimes $\left(\tau_{\text {hyd }}=\right.$ $\frac{1}{k_{\mathrm{n}}^{\mathrm{N}}}$ ) determined for the primary and secondary organonitrates in the present work for reactions in $55 \mathrm{wt} \% \mathrm{D}_{2} \mathrm{SO}_{4}$ solutions. For these highly concentrated acid solutions, $k_{\mathrm{eff}}^{\mathrm{S}}$ and $k_{\text {eff }}^{\mathrm{N}}$ are best interpreted through the excess acidity framework 
(Cox and Yates, 1978), rather than Eq. (6). We have successfully applied the excess acidity method in the past to acidcatalyzed aldol condensation reactions (Casale et al., 2007) and to the acid-catalyzed hydrolysis of primary organosulfates (Minerath et al., 2008). The following linear equation was found to fit the observed acid-dependence of the rate constants for the kinetics of hydrolysis of primary organosulfates:

$\left(\log k_{\text {phenom }}-\log C_{\mathrm{H}+}-\log a_{\mathrm{w}}\right)=m X+b$

As $X$, the excess acidity parameter, is analogous to $\log \left[\mathrm{H}^{+}\right]$, this analysis is essentially a more sophisticated version of the "log-log" plotting exercise often used to determine reaction rate orders, but that is instead applied here to find the effective $\mathrm{H}^{+}$rate order (the slope, $m$, in Eq. 8) for the acid-catalyzed process. The intercept, $b$, in Eq. (8) represents the value of $\log k_{\text {phenom }}$ at infinite dilution $(X=0)$. In order to analyze the present results in terms of the excess acidity framework, the pseudo first-order rate constants must be converted to the appropriate second order rate constants (i.e. $k_{\text {phenom }}=k_{\text {eff }}^{\mathrm{S}} /\left[\mathrm{H}_{2} \mathrm{O}\right]$ ), where $\left[\mathrm{H}_{2} \mathrm{O}\right]$ is the formal molality of water for the acid solutions used. Parameterized values for $X, \log C_{\mathrm{H}+}$, and $\log a_{\mathrm{w}}$ as a function of sulfuric acid weight percent are given in our previous work (Minerath et al., 2008). For methyl sulfate, the regression parameters were found to be $m=1.152$ and $b=-10.33$, indicating that the hydrolysis kinetics are acid-catalyzed with a rate order of nearly one, as expected. A similar analysis for the acid-dependent (over the range $45-65 \mathrm{wt} \% \mathrm{D}_{2} \mathrm{SO}_{4}$ ) hydrolysis of ethyl nitrate investigated in this work yielded values of $m=1.94$ and $b=-11.3$. While this result appears to indicate that the acid-dependence of hydrolysis is approximately second order for organonitrates, we believe that it is more likely that the $\mathrm{HNO}_{3}$ hydrolysis coproduct is leading to the observation of a larger than expected acid-dependence. It has been previously demonstrated that the concentration of the nitronium ion $\left(\mathrm{NO}_{2}^{+}\right)$exponentially increases over this range of sulfuric acid concentrations (Iraci et al., 2007). It is also possible that the nitrosyl ion $\left(\mathrm{NO}^{+}\right)$, which is also known to be present in sulfuric acid solutions (Burley and Johnston, 1992), plays a role (Shen and Ruest, 1980). In any case, it is likely that either $\mathrm{NO}^{+}$- and $\mathrm{NO}_{2}^{+}$-driven reactions are enhancing the loss of ethyl nitrate beyond the simple first order acid-catalyzed expectation. As we discuss in a subsequent section, our observation of more highly oxidized reaction products from the primary and secondary organonitrate reaction systems, but not in the reactions of organosulfates, is strong evidence for the participation of $\mathrm{NO}^{+}$- or $\mathrm{NO}_{2}^{+}$-driven chemistry at these very high sulfuric acid concentrations.

For hydrolysis reactions carried out in $55 \mathrm{wt} \% \mathrm{D}_{2} \mathrm{SO}_{4}$, the primary organosulfate hydrolysis lifetimes were previously determined (Minerath et al., 2008) to range from 71 to $260 \mathrm{~h}$, while the primary and secondary organonitrate hydrolysis lifetimes determined in the present work ranged from 1.5 to $2.5 \mathrm{~h}$. Similar to the tertiary hydrolysis results, these results indicate that hydrolysis of primary and secondary organonitrates is significantly more kinetically efficient than is the hydrolysis of primary and secondary organosulfates. However, unlike the tertiary hydrolysis results, adjacent $\mathrm{OH}$ groups appear to make little difference in the hydrolysis lifetimes. This is likely due to the differences in interaction of $\mathrm{OH}$ groups with the active site of the transition states for the acid-catalyzed mechanism (the transition state is most likely protonated) as compared to the neutral mechanism (the transition state is most likely unprotonated).

Previously, the hydrolysis kinetics of methyl, ethyl, isopropyl, and tert-butyl nitrates in water/alcohol mixtures had been investigated at elevated temperatures (Baker and Easty, 1952). If the water content of the water/alcohol solutions and the activation energies reported in the Baker and Easty work are used to derive effective room temperature first order aqueous solution rate constants (so as to be comparable to the rate constants determined in the present study), the lifetimes for the neutral hydrolysis of methyl, ethyl, isopropyl and tert-butyl nitrates are found to be 13000,26000 , 5300 and $0.087 \mathrm{~h}$, respectively. While the extrapolation of the Baker and Easty data is quite approximate, there is good order of magnitude agreement between the neutral hydrolysis lifetime of the tertiary organonitrate in that work (tert-butyl nitrate) with the tertiary hydroxy organonitrates studied in the present work ( $\tau_{\text {hyd }}=0.019-0.030 \mathrm{~h}$ ). The extremely long neutral hydrolysis lifetimes for the primary and secondary organonitrates measured by Baker and Easty are also consistent with the neutral hydrolysis rate constant lower limits we previously determined for several primary isoprene-derived organonitrates $\left(\tau_{\text {hyd }}>2500 \mathrm{~h}\right.$ ) (Darer et al., 2011).

\subsection{Identification of reaction products}

For most of the organosulfate experiments, the alcohols formed by hydrolysis were the only other species observed. However, at very high sulfuric acid concentrations (65 wt \% $\mathrm{D}_{2} \mathrm{SO}_{4}$ ), the tertiary diol 2-methyl-1,2-propanediol was observed to undergo a pinacol dehydration rearrangement to 2methyl-propanal (Loudon, 1984). For the reactions of primary and secondary organonitrates, which were studied only at very high sulfuric acid concentrations, several species in addition to alcohols were observed. In particular, we carefully investigated the products formed from the reaction of 3nitrato-2-butanol (present at an initial concentration of about $0.10 \mathrm{M})$ in $50 \mathrm{wt} \% \mathrm{D}_{2} \mathrm{SO}_{4}$. At early times in the reactive loss of 3-nitrato-2-butanol, the hydrolysis product, 2,3butanediol, was the only reaction product observed. However, at later times, 3-hydroxy-2-butanone and acetic acid were also observed (see Fig. 4; the identity of these species was confirmed by reference to standards). As the reaction continued towards complete loss of 3-nitrato-2-butanol, the concentration of 3-hydroxy-2-butanone was observed to decrease somewhat, while the concentration of acetic acid continued to rise. After all of the 3-nitrato-2-butanol had 


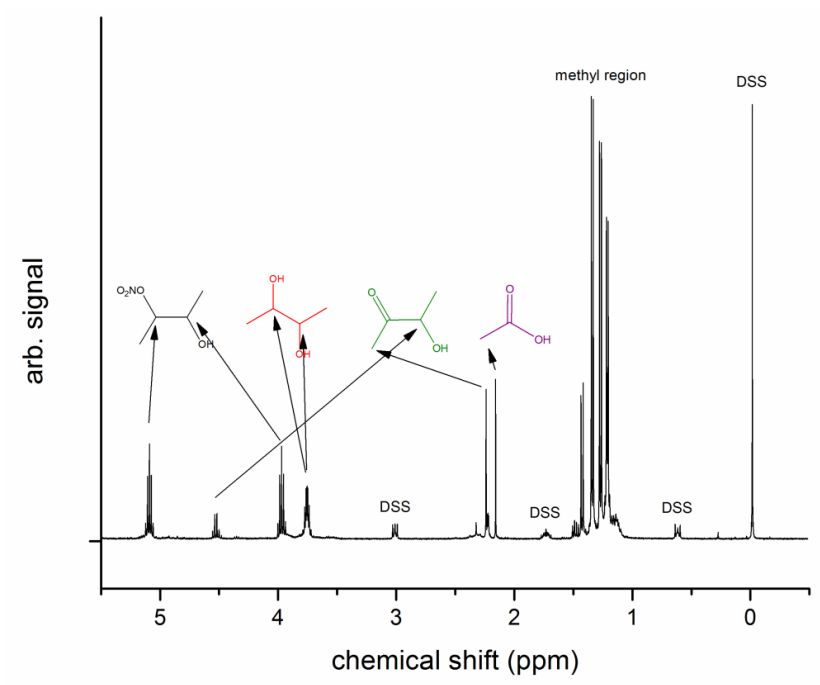

Fig. 4. NMR spectrum taken during the reaction of 3-nitrato-2butanol in $50 \mathrm{wt} \% \mathrm{D}_{2} \mathrm{SO}_{4}$ referenced relative to the internal standard, DSS. The specific proton signal assignments are mainly indicated by arrows pointing to specific carbon centers. In the methyl region, in order of decreasing chemical shift, the four doublet peaks are due to methyl groups in 3-hydroxy-2-butanone, 3-nitrato-2butanol (2 peaks), and 2,3-butanediol, respectively.

been consumed, the products consisted of about $75 \% 2,3-$ butanediol, $15 \%$ 3-hydroxy-2-butanone, and $10 \%$ acetic acid. Unlike the tertiary organonitrates, no organosulfates were observed to form from primary and secondary organonitrates at these very high sulfuric acid conditions. The observed product distribution is consistent with the following mechanism:

$$
\begin{aligned}
& \mathrm{CH}_{3} \mathrm{CH}(\mathrm{OH}) \mathrm{CH}\left(\mathrm{ONO}_{2}\right) \mathrm{CH}_{3}+\mathrm{H}_{2} \mathrm{O} \stackrel{\mathrm{H}^{+}}{\longrightarrow} \\
& \mathrm{CH}_{3} \mathrm{CH}(\mathrm{OH}) \mathrm{CH}(\mathrm{OH}) \mathrm{CH}_{3}+\mathrm{HNO}_{3}
\end{aligned}
$$

$$
\begin{aligned}
& \mathrm{CH}_{3} \mathrm{CH}(\mathrm{OH}) \mathrm{CH}(\mathrm{OH}) \mathrm{CH}_{3}+\mathrm{HNO}_{3} \rightarrow \\
& \mathrm{CH}_{3} \mathrm{C}(=\mathrm{O}) \mathrm{CH}(\mathrm{OH}) \mathrm{CH}_{3}+\mathrm{HONO}+\mathrm{H}_{2} \mathrm{O}
\end{aligned}
$$

$$
\begin{aligned}
& \mathrm{CH}_{3} \mathrm{C}(=\mathrm{O}) \mathrm{CH}(\mathrm{OH}) \mathrm{CH}_{3}+2 \mathrm{HNO}_{3} \rightarrow \\
& 2 \mathrm{CH}_{3} \mathrm{C}(=\mathrm{O}) \mathrm{OH}+2 \mathrm{HONO}
\end{aligned}
$$

The industrial process for adipic acid (one of intermediates used in the manufacture of nylon and polyurethane) (Shimizu et al., 2000) involves the nitric acid induced oxidation of cyclohexanol, and is believed to follow a similar mechanism (van Asselt and van Krevelen, 1963). In order to test this hypothesis, a $0.10 \mathrm{M}$ 2,3-butanediol/ $/ 0.10 \mathrm{M} \mathrm{DNO}_{3} / 50 \mathrm{wt} \%$ $\mathrm{D}_{2} \mathrm{SO}_{4}$ solution was prepared in a separate experiment and monitored. The identity and the concentration of the observed products were very similar to those obtained in the 3nitrato-2-butanol experiment, thus confirming the role of nitric acid in the formation of the more highly oxidized organic species. To further test the role of nitric acid in the formation of oxidized organic species, a $0.10 \mathrm{M} 2,3$-butanediol/ $/ 0.20 \mathrm{M}$ $\mathrm{DNO}_{3}$ solution was prepared in a separate experiment and monitored. In this case no appreciable reaction was observed, even though the nitric acid concentration was higher than in the experiments which included high concentrations of sulfuric acid. Therefore, since both highly concentrated sulfuric acid and nitric acid were found to be necessary to produce the oxidized species, we surmise that either the nitronium or nitrosyl ion is the actual reactive species in these systems (Iraci et al., 2007). Similarly, ethyl and isopropyl nitrate were found to produce, in addition to the expected hydrolysis alcohol products, formic and acetic acid in strong sulfuric acid solutions.

As was mentioned in the experimental section, it was noticed that gas was also evolved from the organonitrate systems in strong sulfuric acid solutions, and the gas evolution from the reaction of 3-nitrato-2-butanol in a $55 \mathrm{wt} \% \mathrm{D}_{2} \mathrm{SO}_{4}$ was quantitatively investigated. The FTIR spectrum of the collected gas indicated that the vast majority of the sample consisted of $\mathrm{N}_{2} \mathrm{O}$ (confirmed by comparison to a reference spectrum). Using the infrared cross section determined from the reference spectrum, the observed IR absorbance of the sample, the gas volume of the sampling system, and the initial amount of 3-nitrato-2-butanol, it was determined that, within the error of the measurement $(\sim 30 \%)$, all of the nitrogen content originally present as 3-nitrato-2-butanol had been converted to $\mathrm{N}_{2} \mathrm{O}$. Previously, $\mathrm{N}_{2} \mathrm{O}$ evolution from sulfuric acid solutions was rationalized via a nitrosyl ion-based mechanism (Wiesen et al., 1995):

$$
2 \mathrm{HONO}+2 \mathrm{H}_{2} \mathrm{SO}_{4} \rightarrow 2 \mathrm{NO}^{+} \mathrm{HSO}_{4}^{-}+2 \mathrm{H}_{2} \mathrm{O}
$$

$$
\begin{aligned}
& 2 \mathrm{NO}^{+} \mathrm{HSO}_{4}^{-}+2 \mathrm{HONO}+2 \mathrm{H}_{2} \mathrm{O} \rightarrow(\mathrm{HNO})_{2}+\mathrm{NO} \\
& +2 \mathrm{HNO}_{3}+2 \mathrm{H}_{2} \mathrm{SO}_{4}
\end{aligned}
$$

$(\mathrm{HNO})_{2} \rightarrow \mathrm{N}_{2} \mathrm{O}+\mathrm{H}_{2} \mathrm{O}$

Since we showed that the nitric acid induced oxidation of alcohols also likely produces $\mathrm{HONO}$, it seems probable that the $\mathrm{N}_{2} \mathrm{O}$ observed in our experiments is produced according to the mechanism proposed by Wiesen et al. It is also worth noting that the industrial process for adipic acid also produces large quantities of $\mathrm{N}_{2} \mathrm{O}$, likely via the same process as outlined above. Before $\mathrm{N}_{2} \mathrm{O}$ abatement strategies were implemented at adipic acid plants during the 1990s, adipic acid production was estimated to be the largest global industrial $\mathrm{N}_{2} \mathrm{O}$ source (Shimizu et al., 2000).

\section{Atmospheric implications}

In our previous work on isoprene-derived organonitrates and organosulfates, we used kinetics arguments to contend that only the tertiary organonitrate species were likely to undergo 
hydrolysis under typical SOA conditions $(\mathrm{pH}>0)$ and lifetimes (several days) (Darer et al., 2011). The present work indicates that the standard state free energies of hydrolysis are negative for all studied organonitrates and organosulfates, including all potential isoprene-derived organonitrate and organosulfate isomers. Therefore, the thermodynamics results suggest that all possible isoprene-derived organosulfates and primary organonitrates are metastable species with respect to the corresponding alcohols and provide further support for the contention that kinetic barriers are responsible for the observation of isoprene-derived organosulfates and organonitrates in SOA. Two caveats: (1) other catalysts may be present in ambient SOA (such as metals) which might facilitate a quicker equilibration (i.e. conversion to alcohols) of primary and secondary systems and (2) for SOA with very low water content and very high nitrate or sulfate content conditions very different than standard state - it may be possible for tertiary organonitrates and organosulfates to be thermodynamically stable; however, without accurate $-T \Delta S_{\text {hyd }}$ values for the isoprene-derived species, it is not possible to quantitatively predict the conditions required for such stability.

The more general results presented in this work largely validate the results previously obtained for isoprene-derived organonitrates and organosulfates. Specifically, the primary and secondary organonitrates and organosulfates were found to only undergo efficient hydrolysis at acidities much greater than typically found on SOA. For example, if the hydrolysis lifetime for ethyl nitrate measured at $55 \mathrm{wt} \% \mathrm{D}_{2} \mathrm{SO}_{4}$ in the present work is extrapolated to the lowest $\mathrm{pH}$ typically observed in SOA (Zhang et al., 2007) $(\mathrm{pH}=0$; which corresponds to a $14 \mathrm{wt} \% \mathrm{D}_{2} \mathrm{SO}_{4}$ aqueous solution) using a first order excess acidity model, a value of about $500 \mathrm{~h}$ is obtained, which is roughly 10 times longer than typical SOA lifetimes. Therefore, while the present thermodynamic results indicate that these species are likely only metastable with respect to the corresponding alcohols, the kinetic barriers are too great for these species to transform efficiently to alcohols on SOA. The hydrolysis of tertiary organonitrates was again found to be highly efficient even at neutral conditions. Similarly, a previous laboratory study on the formation of organonitrates from 2-methyl-1-alkenes found that SOA filter samples containing tertiary organonitrates were much less stable than secondary organonitrates (Matsunaga and Ziemann, 2010). Thus, it is likely that all tertiary organonitrates are unstable on SOA under typical ambient conditions and this result rationalizes previous observations of efficient organonitrate hydrolysis on aerosols (Nguyen et al., 2011; Day et al., 2010). While we did not carry out temperature dependent kinetics hydrolysis kinetics measurements, it is likely that the hydrolysis kinetics of tertiary organonitrates on cold upper tropospheric aerosols is significantly slower. For example, if the rule of thumb that the rate constant doubles for every $10 \mathrm{~K}$ increase in temperature is assumed, the predicted hydrolysis lifetime of the isoprene-derived organonitrate, 2-methyl-2- nitrato-1,3,4-butanetriol at $226 \mathrm{~K}$ would be on the order of days, which could allow sufficent time for long-range transport of this particular organonitrate. However, these aerosols would also be very highly acidic, and other mechanisms (such as the nitronium- or nitrosyl-assisted fast reaction observed in the primary and secondary organonitrates at high acid concentraitons in the present work) might lead to efficient organonitrate reaction under these conditions.

The observation in the present work that 2-nitrato-1propanol can undergo a nucleophilic substitution reaction with sulfate to form 2-sulfato-1-propanol provides further support for our previous hypothesis that such reactions on SOA might explain why organosulfates are more commonly observed than are organonitrates. The new results for tertiary organosulfates indicate that, unlike the isoprene-derived tertiary organosulfate case, some tertiary organosulfates (particularly those with fewer adjacent $\mathrm{OH}$ groups and those with allylic functionality) might be unstable on SOA. In particular, all three tertiary organosulfates under study in the present work were found to have neutral hydrolysis lifetimes that are less than the typical SOA lifetime. Therefore, it is possible that organosulfates formed from methacrolein, a major first generation gas phase isoprene oxidation product with a tertiary carbon center, might not be stable on SOA, while organosulfates formed from methyl vinyl ketone, another major first generation gas phase isoprene oxidation product with a secondary carbon center, would be expected to be stable on SOA.

We also found that organonitrates that undergo hydrolysis under conditions of very high sulfuric acid content can be oxidized further by the presence of the hydrolysis product, nitric acid. We also established that these conditions could lead to the reduction of nitrate to $\mathrm{N}_{2} \mathrm{O}$, a potent greenhouse gas. However, it seems unlikely that SOA acidities are ever high enough for these processes to be efficient and atmospherically relevant.

\section{Conclusions}

In general, the new results presented here confirmed a number of structure-activity relationships that we had previously uncovered in our investigation of the hydrolysis reactions of isoprene-derived organonitrates and organosulfates (Darer et al., 2011). The new thermodynamics results suggest that organonitrates and organosulfates are generally thermodynamically unstable with respect to the corresponding alcohols at standard state conditions. Therefore, the presence of these species in ambient SOA is likely due to the presence of high kinetic barriers to hydrolysis for these particular species. The presence of adjacent $\mathrm{OH}$ groups was found to generally reduce the enthalpy of hydrolysis for all organonitrates and organosulfates (making these species less stable relative to the corresponding alcohols) and to decrease the rate of hydrolysis for tertiary organonitrates and 
organosulfates (making these species convert more slowly to the corresponding alcohols). For example, On the other hand, the presence of adjacent $\mathrm{OH}$ groups had little effect on the acid-catalyzed hydrolysis of primary and secondary organonitrates. Due to the extremely high acidity levels required for efficient hydrolysis, we assert that most, if not all, primary and secondary organonitrates and organosulfates are likely to be stable at relevant SOA acidities and lifetimes. The very efficient neutral hydrolysis of tertiary organonitrates suggests that these species are highly unstable on ambient SOA, particularly at elevated relative humidities, with lifetimes significantly shorter $(0.019-0.67 \mathrm{~h})$ than typical SOA lifetimes (several days) While our previous work indicated that isoprene-derived tertiary organosulfates are likely to be stable on SOA, the present work revealed that other atmospherically relevant tertiary organosulfates might undergo efficient hydrolysis on SOA.

Acknowledgements. This work was supported by the National Science Foundation under Grant No. 0753103.

Edited by: R. Cohen

\section{References}

Altieri, K. E., Turpin, B. J., and Seitzinger, S. P.: Oligomers, organosulfates, and nitrooxy organosulfates in rainwater identified by ultra-high resolution electrospray ionization FTICR mass spectrometry, Atmos. Chem. Phys., 9, 2533-2542, doi:10.5194/acp-9-2533-2009, 2009.

Baker, J. W. and Easty, D. M.: Hydrolytical decomposition of esters of nitric acid. I. General experimental techniques. Alkaline hydrolysis and neutral solvolysis of methyl, ethyl, isopropyl, and tertbutyl nitrates in aqueous alcohol, J. Chem. Soc., 1952, 1193 1207, 1952.

Burley, J. D. and Johnston, H. S.: Nitrosyl sulfuric acid and stratospheric aerosols, Geophys. Res. Lett., 19, 1363-1366, 1992.

Cappa, C. D. and Elrod, M. J.: A computational investigation of the electron affinity of $\mathrm{CO}_{3}$ and the thermodynamic feasibility of $\mathrm{CO}_{3}^{-}\left(\mathrm{H}_{2} \mathrm{O}\right)_{n}+\mathrm{ROOH}$ reactions, Phys. Chem. Chem. Phys., 3, 2986-2994, 2001.

Carlton, A. G., Wiedinmyer, C., and Kroll, J. H.: A review of Secondary Organic Aerosol (SOA) formation from isoprene, Atmos. Chem. Phys., 9, 4987-5005, doi:10.5194/acp-9-4987-2009, 2009.

Casale, M., Richman, A., Elrod, M., Garland, R., Beaver, M., and Tolbert, M.: Kinetics of acid-catalyzed aldol condensation reactions of aliphatic aldehydes, Atmos. Environ., 41, 6212-6224, doi:10.1016/j.atmosenv.2007.04.002, 2007.

Chan, M. N., Surratt, J. D., Claeys, M., Edgerton, E. S., Tanner, R. L., Shaw, S. L., Zheng, M., Knipping, E. M., Eddingsaas, N. C., Wennberg, P. O., and Seinfeld, J. H.: Characterization and quantification of isoprene-derived epoxydiols in ambient aerosol in the southeastern United States, Environ. Sci. Technol., 44, 45904596, 2010.

Claeys, M., Graham, B., Vas, G., Wang, W., Vermeylen, R., Pashynska, V., J., C., Guyon, P., Andreae, M. O., Artaxo, P., and Maenhaut, W.: Formation of secondary organic aerosols through photooxidation of isoprene, Science, 303, 1173-1176, doi:10.1126/science.1092805, 2004.

Clark, D. J. and Williams, G.: Esterification by sulphuric acid, J. Chem. Soc., 4218-4221, 1957.

Cole-Filipiak, N. C., O'Connor, A. E., and Elrod, M. J.: Kinetics of the hydrolysis of atmospherically relevant isoprene-derived hydroxy epoxides, Environ. Sci. Technol., 44, 6718-6723, 2010.

Cox, R. A. and Yates, K.: Excess acidities. A generalized method for the determination of basicities in aqueous acid mixtures, J. Am. Chem. Soc., 100, 3861-3867, 1978.

Curtiss, L. A., Raghavachari, K., Redfern, P. C., and Pople, J. A.: Assessment of Gaussian-2 and density functional theories for the computation of enthalpies of formation, J. Chem. Phys., 106, 1063-1079, 1997.

Darer, A. I., Cole-Filipiak, N. C., O'Connor, A. E., and Elrod, M. J.: Formation and stability of atmospherically relevant isoprenederived organosulfates and organonitrates, Environ. Sci. Technol., 45, 1895-1902, 2011.

Day, D. A., Liu, S., Russell, L. M., and Ziemann, P. J.: Organonitrate group concentrations in submicron particles with high nitrate and organic fractions in coastal southern California, Atmos. Environ., 44, 1970-1979, doi:10.1016/j.atmosenv.2010.02.045, 2010.

Eddingsaas, N. C., VanderVelde, D. G., and Wennberg, P. O.: Kinetics and products of the acid-catalyzed ring-opening of atmospherically relevant butyl epoxy alcohols, J. Phys. Chem. A, 114, 8106-8113, doi:10.1021/Jp103907c, 2010.

Frisch, M. J. T., Schlegel, G. W., Scuseria, H. B., Robb, G. E., Cheeseman, M. A., Montgomery Jr., J. R., Vreven, J. A., Kudin, T., Burant, K. N., Millam, J. C., Iyengar, J. M., Tomasi, S. S., Barone, J., Mennucci, V., Cossi, B., Scalmani, M., Rega, G., Petersson, N., Nakatsuji, G. A., Hada, H., Ehara, M., Toyota, M., Fukuda, K., Hasegawa, R., Ishida, J., Nakajima, M., Honda, T., Kitao, Y., Nakai, O., Klene, H., Li, M., Knox, X., Hratchian, J. E., Cross, H. P., Bakken, J. B., Adamo, V., Jaramillo, C., Gomperts, J., Stratmann, R., Yazyev, R. E., Austin, O., Cammi, A. J., Pomelli, R., Ochterski, C., Ayala, J. W., Morokuma, P. Y., Voth, K., Salvador, G. A., Dannenberg, P., Zakrzewski, J. J., Dapprich, V. G., Daniels, S., Strain, A. D., Farkas, M. C., Malick, O., Rabuck, D. K., Raghavachari, A. D., Foresman, K., Ortiz, J. B., Cui, J. V., Baboul, Q., Clifford, A. G., Cioslowski, S., Stefanov, J., Liu, B. B., Liashenko, G., Piskorz, A., Komaromi, P., Martin, I., Fox, R. L., Keith, D. J., Al-Laham, T., Peng, M. A., Nanayakkara, C. Y., Challacombe, A., Gill, M., Johnson, P. M. W., Chen, B., Wong, W., Gonzalez, C., and Pople, J. A.: Gaussian 03, Gaussian, Inc., Wallingford, CT, 2003.

Froese, R. D. J., Humbel, S., Svensson, M., and Morokuma, K.: IMOMO(G2MS): A new high-level G2-like method for large molecules and its applications to Diels-Alder reactions, J. Phys. Chem. A, 101, 227-233, 1997.

Froyd, K. D., Murphy, S. M., Murphy, D. M., De Gouw, J. A., Eddingsaas, N. C., and Wennberg, P. O.: Contribution of isoprenederived organosulfates to free tropospheric aerosol mass, P. Natl. Acad. Sci., 107, 21360-21365, 2010.

Gómez-González, Y., Surratt, J. D., Cuyckens, F., Szmigielski, R., Vermeylen, R., Jaoui, M., Lewandowski, M., Offenberg, J. H., Kleindienst, T. E., Edney, E. O., Blockhuys, F., Van Alsenoy, C., Maenhaut, W., and Claeys, M.: Characterization of organosulfates from the photooxidation of isoprene and unsaturated fatty 
acids in ambient aerosol using liquid chromatography/(-) electrospray ionization mass spectrometry, J. Mass Spectrom., 43, 371-382, doi:10.1002/jms.1329, 2008.

Guenther, A., Karl, T., Harley, P., Wiedinmyer, C., Palmer, P. I., and Geron, C.: Estimates of global terrestrial isoprene emissions using MEGAN (Model of Emissions of Gases and Aerosols from Nature), Atmos. Chem. Phys., 6, 3181-3210, doi:10.5194/acp-63181-2006, 2006.

Hallquist, M., Wenger, J. C., Baltensperger, U., Rudich, Y., Simpson, D., Claeys, M., Dommen, J., Donahue, N. M., George, C., Goldstein, A. H., Hamilton, J. F., Herrmann, H., Hoffmann, T., Iinuma, Y., Jang, M., Jenkin, M. E., Jimenez, J. L., Kiendler-Scharr, A., Maenhaut, W., McFiggans, G., Mentel, Th. F., Monod, A., Prévôt, A. S. H., Seinfeld, J. H., Surratt, J. D., Szmigielski, R., and Wildt, J.: The formation, properties and impact of secondary organic aerosol: current and emerging issues, Atmos. Chem. Phys., 9, 5155-5236, doi:10.5194/acp-95155-2009, 2009.

Iraci, L. T., Riffel, B. G., Robinson, C. B., Michelsen, R. R., and Stephenson, R. M.: The acid catalyzed nitration of methanol: formation of methyl nitrate via aerosol chemistry, J. Atmos. Chem., 58, 253-266, 2007.

Kua, J., Hanley, S. W., and De Haan, D. O.: Thermodynamics and kinetics of glyoxal dimer formation: a computational study, J. Phys. Chem. A, 112, 66-72, 2008.

Lockwood, A. L., Shepson, P. B., Fiddler, M. N., and Alaghmand, M.: Isoprene nitrates: preparation, separation, identification, yields, and atmospheric chemistry, Atmos. Chem. Phys., 10, 6169-6178, doi:10.5194/acp-10-6169-2010, 2010.

Loudon, G. M.: Organic Chemistry, Addison-Wesley, Reading, Massachusetts, 1984.

Matsunaga, A. and Ziemann, P. J.: Atmospheric Chemistry Special Feature: Yields of -hydroxynitrates, dihydroxynitrates, and trihydroxynitrates formed from $\mathrm{OH}$ radical-initiated reactions of 2-methyl-1-alkenes, P. Natl. Acad. Sci., 107, 6664-6669, doi:10.1073/pnas.0910585107, 2010.

Minerath, E. C. and Elrod, M. J.: Assessing the potential for diol and hydroxy sulfate ester formation from the reaction of epoxides in tropospheric aerosols, Environ. Sci. Technol., 43, 1386-1392, doi:10.1021/es8029076, 2009.

Minerath, E. C., Casale, M. T., and Elrod, M. J.: Kinetics feasibility study of alcohol sulfate esterification reactions in tropospheric aerosols, Environ. Sci. Technol., 42, 4410-4415, 2008.

Minerath, E. C., Schultz, M. P., and Elrod, M. J.: Kinetics of the reactions of isoprene-derived epoxides in model tropospheric aerosol solutions, Environ. Sci. Technol., 43, 8133-8139, doi:10.1021/es902304p, 2009.

Muthuramu, K., Shepson, P. B., and O’Brien, J. M.: Preparation, analysis, and atmospheric production of multifunctional organic nitrates, Environ. Sci. Technol., 27, 1117-1124, 1993.

Ng, N. L., Kwan, A. J., Surratt, J. D., Chan, A. W. H., Chhabra, P. S., Sorooshian, A., Pye, H. O. T., Crounse, J. D., Wennberg, P. O., Flagan, R. C., and Seinfeld, J. H.: Secondary organic aerosol (SOA) formation from reaction of isoprene with nitrate radicals $\left(\mathrm{NO}_{3}\right)$, Atmos. Chem. Phys., 8, 4117-4140, doi:10.5194/acp-84117-2008, 2008.

Nguyen, T. B., Roach, P. J., Laskin, J., Laskin, A., and Nizkorodov, S. A.: Effect of humidity on the composition of isoprene photooxidation secondary organic aerosol, Atmos. Chem. Phys., 11,
6931-6944, doi:10.5194/acp-11-6931-2011, 2011.

Nozière, B., Ekström, S., Alsberg, T., and Holmström, S.: Radical-initiated formation of organosulfates and surfactants in atmospheric aerosols, Geophys. Res. Lett., 37, L05806, doi:10.1029/2009g1041683, 2010.

Paulot, F., Crounse, J. D., Kjaergaard, H. G., Kurten, A., St. Clair, J. M., Seinfeld, J. H., and Wennberg, P. O.: Unexpected epoxide formation in the gas-phase photooxidation of isoprene, Science, 325, 730-733, doi:10.1126/science.1172910, 2009.

Perring, A. E., Bertram, T. H., Wooldridge, P. J., Fried, A., Heikes, B. G., Dibb, J., Crounse, J. D., Wennberg, P. O., Blake, N. J., Blake, D. R., Brune, W. H., Singh, H. B., and Cohen, R. C.: Airborne observations of total $\mathrm{RONO}_{2}$ : new constraints on the yield and lifetime of isoprene nitrates, Atmos. Chem. Phys., 9, 1451-1463, doi:10.5194/acp-9-1451-2009, 2009a.

Perring, A. E., Wisthaler, A., Graus, M., Wooldridge, P. J., Lockwood, A. L., Mielke, L. H., Shepson, P. B., Hansel, A., and Cohen, R. C.: A product study of the isoprene $+\mathrm{NO}_{3}$ reaction, Atmos. Chem. Phys., 9, 4945-4956, doi:10.5194/acp-9-4945-2009, 2009b.

Pope III, C. A. and Dockery, D. W.: Health effects of fine particulate air pollution: lines that connect, J. Air Waste Manage., 56, 709742, 2006.

Ranschaert, D. L., Schneider, N. J., and Elrod, M. J.: Kinetics of the $\mathrm{C}_{2} \mathrm{H}_{5} \mathrm{O}_{2}+\mathrm{NO}_{\mathrm{x}}$ reactions: temperature dependence of the overall rate constant and the $\mathrm{C}_{2} \mathrm{H}_{5} \mathrm{ONO}_{2}$ Branching Channel of $\mathrm{C}_{2} \mathrm{H}_{5} \mathrm{O}_{2}+\mathrm{NO}$, J. Phys. Chem. A, 104, 5758-5765, 2000.

Rudzinski, K. J., Gmachowski, L., and Kuznietsova, I.: Reactions of isoprene and sulphoxy radical-anions - a possible source of atmospheric organosulphites and organosulphates, Atmos. Chem. Phys., 9, 2129-2140, doi:10.5194/acp-9-2129-2009, 2009.

Shen, C. Y. and Ruest, D. A.: Production of diglycolic acid by nitric acid oxidation of diethylene glycol, Ind. Eng. Chem. Process Des. Dev., 19, 401-404, 1980.

Shimizu, A., Tanaka, K., and Fujimori, M.: Abatement technologies for $\mathrm{N}_{2} \mathrm{O}$ emissions in the adipic acid industry, Chemosphere, 2, 425-434, 2000.

Surratt, J. D., Lewandowski, M., Offenberg, J. H., Jaoui, M., Kleindienst, T. E., Edney, E. O., and Seinfeld, J. H.: Effect of acidity on secondary organic aerosol formation from isoprene, Environ. Sci. Technol., 41, 5363-5369, 2007.

Surratt, J. D., Gómez-González, Y., Chan, A. W. H., Vermeylen, R., Shahgholi, M., Kleindienst, T. E., Edney, E. O., Offenberg, J. H., Lewandowski, M., Jaoui, M., Maenhaut, W., Claeys, M., Flagan, R. C., and Seinfield, J. H.: Organosulfate formation in biogenic secondary organic aerosol, J. Phys. Chem. A, 112, 8345-8378, 2008.

Surratt, J. D., Chan, A. W. H., Eddingsaas, N. C., Chan, M., Loza, C. L., Kwan, A. J., Hersey, S. P., Flagan, R. C., Wennberg, P. O., and Seinfeld, J. H.: Reactive intermediates revealed in secondary organic aerosol formation from isoprene, P. Natl. Acad. Sci., 107, 6640-6645, 2010.

Szmigielski, R., Vermeylen, R., Dommen, J., Metzger, A., Maenhaut, W., Baltensperger, U., and Claeys, M.: The acid effect in the formation of 2-methyltetrols from the photooxidation of isoprene in the presence of $\mathrm{NO}_{\mathrm{x}}$, Atmos. Res., 98, 183-189, doi:10.1016/j.atmosres.2010.02.012, 2010.

Tomasi, J., Mennucci, B., and Cammi, R.: Quantum mechanical continuum solvation models, Chem. Rev., 105, 2999-3093, 
2005.

van Asselt, W. J. and van Krevelen, D. W.: The preparation of adipic acid by oxidation of cyclohexanol and cyclohexanone with nitric acid. I. Reaction mechanism, Recl. Trav. Chim. Pay B, 82, 5167, 1963.

Wang, W., Kourtchev, I., Graham, B., Cafmeyer, J., Maenhaut, W., and Claeys, M.: Characterization of oxygenated derivatives of isoprene related to 2-methyltetrols in Amazonian aerosols using trimethylsilylation and gas chromatography/ion trap mass spectrometry, Rapid Commun. Mass Spectrom., 19, 1343-1351, doi:10.1002/rcm.1940, 2005.

Wexler, A. S. and Clegg, S. L.: Atmospheric aerosol models for systems including the ions $\mathrm{H}^{+}, \mathrm{NH}_{4}^{+}, \mathrm{Na}^{+}, \mathrm{SO}_{4}^{2-}$, $\mathrm{NO}_{3}^{-}, \mathrm{Cl}^{-}, \mathrm{Br}^{-}$, and $\mathrm{H}_{2} \mathrm{O}$, J. Geophys. Res., 107, D000451, doi:10.1029/2001JD000451, 2002.
Wiesen, P., Kleffmann, J., Kurtenback, R., and Becker, K. H.: Mechanistic study of the heterogeneous converison of $\mathrm{NO}_{2}$ into HONO and $\mathrm{N}_{2} \mathrm{O}$ on acid surfaces, Faraday Discuss., 100, 121127, 1995.

Wolfenden, R. and Yuan, Y.: Monoalkyl sulfates as alkylating agents in water, alkylsulfatase rate enhancements, and the "energy-rich" nature of sulfate half-esters, P. Natl. Acad. Sci, 104, 83-86, doi:10.1073/pnas.0609644104, 2007.

Zhang, Q., Jimenez, J. L., Worsnop, D. R., and Canagaratna, M.: A case study of urban particle acidity and its influence on secondary organic aerosol, Environ. Sci. Technol., 41, 3213-3219, 2007. 